\title{
Research priorities in occupational medicine: a survey of United Kingdom personnel managers
}

\author{
J M Harrington, I A Calvert
}

\begin{abstract}
A Delphi survey was carried out in an attempt to identify areas of priority in occupational health that should be targeted by research. Previously 53 occupational physicians identified and ranked these areas. These were then assessed by personel managers. There was considerable agreement on priorities between the two groups with musculoskeletal disorders and stress securing the highest ranking.
\end{abstract}

(Occup Environ Med 1996;53:642-644)

Keywords: Delphi study; priorities

The funding for medical research is reaching crisis point. At present, there are still centres of excellence for research both within academia and industry but financial resources to keep such groups together are diminishing in real and absolute terms. The Medical Research Council and the large charities have found their budgets diminishing for a variety of reasons. Also, government initiatives to concentrate on applied rather than pure research $^{1}$ have further weakened research capability.

In occupational health, research capacity in the United Kingdom is dangerously low although the emergence of the British Occupational Health Research Foundation (BOHRF) in 1991 is encouraging. The Foundation aims to sponsor research identified by its industrial and commercial donors as priority areas. These research areas would be developed into research questions and grants would be awarded after competitive tender. Identifying research priorities has been progressing for some time and a previous survey of medical opinion within the United Kingdom occupational health doctors has focused discussions on key areas. ${ }^{2}$

This first survey canvassed the opinion of 53 senior occupational physicians ( 25 academic and 28 from government or industry). Research priorities were established with the Delphi technique. ${ }^{3}$ That is, the first round of questions asked the respondent to cite three priority areas. Receipt of these questionnaires provided the opportunity to establish five broad areas of interest: the incidence or prevalence or natural history of work related diseases, audit, environmental impact of industrial activity, stress and work, and neuropsychological effects of work exposures. Each broad grouping required a series of subsections ranging from two to eight items. Also 12 other assorted subjects were identified by the respondents to warrant a further list. This second questionnaire requested a rank order for choices for each of the five groups and by subdivisions within each group. From these responses it was possible to identify work related illnesses as the first priority, followed by audit, environmental impact, stress, and finally neuropsychological effects.

After discussions at BOHRF, the industrial and commercial donors considered that a survey of United Kingdom personnel managers would be a useful contribution to the debate. The Institute of Personnel and Development (IPD) offered to assist in the process by providing opportunities to canvass their membership.

\section{Methods}

The IPD has about 54000 members. The survey was restricted to the industrial and commercial sectors with more than 500 members (which excludes fishing, agriculture, manufacture of leather goods, and some central government agencies). A 5\% random sample taken from 39420 corporate members resulted in a postal list of 1971 personnel managers.

Advice from the IPD suggested that the full Delphi process could be bypassed and that managers should be asked to rank the five research priorities areas and their subsections included in the physicians' second mailing but without previous knowledge of the physicians' results. Some modifications of the questions were proposed by the IPD-such as a clear exposition of the meaning of audit in this context, and diseases were restricted to those of backs, work related upper limb disorders, asthma, injuries or accidents, suicide and depression, vibration, and noise (dermatitis was excluded).

As in the previous survey, the summed scores would provide a final rank order with 
Research priorities in occupational medicine: mean ranking of major mean ranking of major occupational physicians with personnel managers higher ranking).

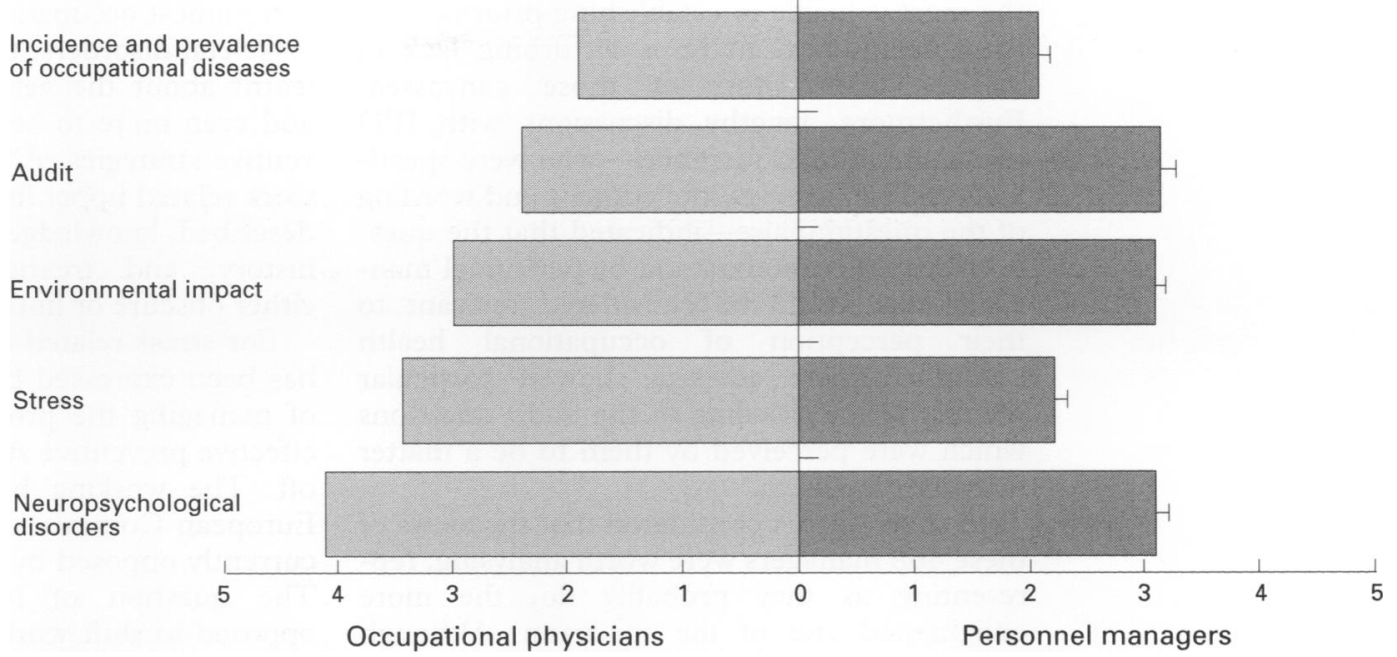

the highest priority choice receiving the lowest numerical score.

\section{Results}

Questionnaires were posted by the IPD to 1971 personnel managers. The response rate was $23 \cdot 7 \%$ (468 completed questionnaires) despite two reminders and a second mailing to non-responders. The response rates by the business sector were provided by the IPD and ranged from $43.6 \%$ (business and personal services) to $8.4 \%$ from central government. However the nature of the questionnaire, which ensured participant anonymity, precluded any analysis by sector.

The ranking system of lowest score for highest priority could, for a question with five choices, results in a score as low as one if all participants rated that choice as one, and as high as five if they all ranked that choice as their last. The scores for each section were summed and an average calculated. The scores for the personnel managers were then compared with the combined scores for academic and industrial physicians. This combination was considered valid as the agreement between the two groups in the earlier survey was remarkably consistent.

For the five broad groups of main research concern (figure) the mean scores ranged from $2 \cdot 1$ to 3.3 for the personnel managers and 1.9 to $4 \cdot 1$ for the physicians.

Although there was less scatter between the scores for the personnel managers the natural history of work related diseases was also their first priority but in their case it was equalled by stress (ranked only fourth by the physicians.) There was little to separate the other three groups.

The supplementary questions for each of these five groups produced little variation in scores between the choices of the personnel managers (range 2.1-3.4) for the seven diseases compared with the physicians (range 2.4-6.2) based on eight diseases. Nevertheless, the top disease for both groups was backs then work related upper limb disorders. They also agreed that the least research effort should be given to vibration and noise.
Although asthma (3.7) was ranked much higher than suicide and depression $(5.5)$ by the physicians, those two conditions were both scored at 2.9 by the personnel managers.

The rank scores within audit and environmental impact were too close to suggest any justification for ranking. For stress, however the personnel managers considered that preventive strategies were the first priority (ranked third by the physicians) then identification of risk factors (ranked first by the physicians). The ranking of eight miscellaneous items which were reduced from 12 for the physicians also showed a narrow range of variability which was too close to distinguish any significant features except to say that the cost effectiveness of occupational health services was the first priority for both sets of respondents.

\section{Discussion}

In the earlier report ${ }^{2}$ it was made clear that such opinion surveys have obvious epidemiological flaws. Indeed, the Delphi technique itself has a tendency to force quarts into pint pots. Nevertheless, the survey showed reasonable unanimity between academia and industry. In the present study, the personnel managers were asked merely to rank the priorities for subjects identified by the physicians. Little opportunity was given to them to develop new ones but a review of the questionnaire by representatives of the IPD produced no suggestions of any further issues of note. The IPD was satisfied that these were the research questions of relevance.

The sampling strategy for the personnel managers and the low response rate does weaken the assertion that this is a representative picture of the opinion of personnel management. However, such a response is slightly higher than the usual experience of the IPD and they indicated that the respondents are likely to be those who are interested in and committed to occupational health issues. Although a representative view cannot be assumed, it is likely from IPD experience that the responders are the "opinion formers" within the profession. Their views would be 
the most valuable in establishing priorities but there seems also to be a disturbing lack of interest from most of those canvassed. Furthermore, lengthy discussions with IPD and some of their members-who were specifically asked to review the content and wording of the questionnaire - indicated that the questions would be understood by personnel managers and would be considered relevant to their perception of occupational health research. These advisers showed particular interest in the wording of the audit questions which were perceived by them to be a matter of current concern.

In short, it was considered that the views of these 468 managers were worth analysing, representing as they probably do, the more enlightened end of the spectrum. Although their ranking decisions were not as clear cut as the physicians, certain messages were discernible.

Firstly, they too thought that a high priority for occupational research was the investigation of the natural history, incidence, and prevalence of work related musculoskeletal disorders in particular, back problems and work related upper limb disorders. Secondly, they viewed stress at work as their second priority (somewhat higher than the physicians) and considered practical strategies more important than risk factor identification, which was the reverse of the physicians' view. Thirdly, they agreed with physicians that of the miscellaneous grouping, the cost effectiveness of occupational health services was the first priority.

There is enough here to make significant progress on research priorities. The Labour Force Survey carried out in 1990 and published in 1993, clearly identified that for self reported illness, musculoskeletal conditions far exceeded those of any other disease category. ${ }^{4}$ The second highest prevalence was for stress and depression. For diseases compensatable by the Department of Social Security (prescribed diseases) the latest figures available are for 1993-4, when carpal tunnel syndrome combined with tenosynovitis and hand or forearm cramp totalled 1202 cases, exceeded only by vibration white finger with 1425 cases. $^{5}$ The Health and Safety Executive in their recent "Good health is good business" campaign also focused on these two issues among others. Finally, in an unprecedented emphasis on occupational health, the Chief Medical Officer's annual report on the state of the public health 1994 makes special mention of mental health problems at work related to stress and employment issues. ${ }^{6}$

These areas of occupational health are numerically important but in these opinion surveys the emphasis was on where new research initiatives are needed, not on the commonest occupational diseases. For musculoskeletal disorders, there remains much to be learnt about the aetiology of such problems and even more to be achieved by way of preventive strategies. Although the prevalence of work related upper limb disorders is quite well described, knowledge of the incidence, natural history, and treatment strategies remains either obscure or hotly disputed.?

For stress related disorders, much concern has been expressed but tried and tested ways of managing the problem and agreement on effective preventive strategies seem a long way off. The working hours directive from the European Commission ${ }^{8}$ may be helpful but is currently opposed by the British Government. The question of long working hours-as opposed to shift work-is an area anecdotally linked to stress but for which high quality epidemiological research is sparse..$^{10}$

In conclusion, despite the epidemiological shortcomings of the survey of personnel managers, those canvassed agreed with the occupational physicians that work related musculoskeletal disorders and stress are of the highest priority for research efforts in occupational health -although they differed on which was the more important of these two. The time has come to move from seeking opinions to action. Good research proposals in these areas should be sought and funded.

We gratefully acknowledge the support and financial help from the British Occupational Health Research Foundation (BOHRF) in the posting of the questionnaires and the statistica analysis. We are also indebted to the Institute of Personnel and Development for their help in the redesign of the questionnaire and for the invaluable access they provided to their memberhip lists. In particular, we would like to to their membership lists. In particular, we would like to thank their policy adviser on employee relations Doug Gummery and senio members of the Institute-Geoff Armstrong, Josie Pottinger, and John Stevens. The idea for extending this survey to personnel managers came from the Management Committee of BOHRF and the results of the study will help in establishing research priorities for the fund

1 Chancellor of the Duchy of Lancaster. Realising our potential: a strategy for science, engineering and technology. London: HMSO, 1993. (Cmnd 2250.)

2 Harrington JM. Research priorities in occupational medicine: a survey of United Kingdom medical opinion by the Delphi technique Occup Environ Med 1994:51:289-94.

3 Delbecq AL van de Ven AH Gustafson DH Group techniques for progam planning. Illinois: Scott Foresman 1975: 83-107.

4 Hodgson JT, Jones JR, Elliott RC, Osman J Self reported work-related illness. London: HSE Books, 1993. (HSE work-related illness. Lon

5 Health and Safety Commission. Health and safety statistics 1994-5. London: HSE Books, 1995.

6 Department of Health. On the state of the public health The annual report of the chief medical officer of the Department of Health for the year 1994. London: HMSO, 1995.

7 Kuorinka I, Forster, eds. Work related musculo skeletal disorders (WMSDS): a reference book for prevention. London Taylor and Francis, 1995.

8 European Commission. Council directive 93/104/EC concerning certain aspects of the organisation of working cerning certain aspects of the organisation of working Vol 36, 13 December 1993. Brussels: EC, 1993.

Harrington JM. Working long hours and health. BMF 1994;308:1581-2.

10 Cooper CL. Working hours and health. Work and Stress $1996 ; 10: 1-4$. 